\title{
Exploring the Versatility of Denim Fabrics - A Review of some Significant Insights on Recent Researches
}

\author{
Gokarneshan N*, Velumani K, Sandipkumar R, Malathi R and Aathira \\ Department of Textile Technology, Park College of engineering and technology, Coimbatore, Tamil Nadu, India
}

Submission: September 19, 2017; Published: February 01, 2018

*Corresponding author: Department of Textile Technology, Park College of engineering and technology, Coimbatore, Tamil Nadu, India,

Email: advaitcbe@rediffmail.com

\begin{abstract}
Considerable research work has been done on denim fabrics during recent years and their properties as well as sustainability well exploited. Nano titanium dioxide has been applied on denim fabrics for imparting multifunctional finishes for value addition adopting three routes - dry exhaust, microencapsulation and nano encapsulation. Efforts have been taken to develop comfortable denim clothing using regenerated cellulose derivatives, maintaining its rustic look for tropical regions. The performance of the developed fabric has been assessed by using evaluation methods. In order to meet the stringent needs so as to withstand global environment focus has been directed on the study of different techniques through which apparel industries are developing textiles with smart functioning, using new sustainable products to provide extra comfort and increased performance in an eco-friendly manner. Sustainability will be crucial for all the denims/jeans brands/Denim manufacturers to withstand in the global environment. Desized indigo denim fabrics have been evaluated for breaking force, spectral characteristics and surface appearance by means of application of special finishes. The findings show that some of them are acceptable only as an effective segment on a garment. The resilience properties of stretch denim fabrics have been studied on the tensile properties and structural parameters by using Kawabata evaluation system. The tensile properties are determined by proportion or polyester and elastane in relation to cotton. The recent years has seen developments in denims. The major focus areas of innovation and development are comfort, performance and environment friendliness of different processes. Recent developments of silk denims which are soft, light and comfortable in all seasons, have added a new dimension to the denim and fashion world.
\end{abstract}

Keywords: Denim fabrics; Multi functional finishes; Nano materials; Stretch; Sustainability; Tensile properties; Silk Denims

\section{Introduction}

Denim though considered to be one of the oldest fabrics in the world yet remains fresh even today. Ever since its inception it has been conventionally produced from $100 \%$ cotton. Since denim is the unique apparel preferred by all age groups and due to its' popularity, a lot of development work has been done in the last few decades. Due to these innovations, a large number of variants of denim are available to the customer today. The expectations from fabrics have changed with developments in textile technology and the consumers' living standards. Modern consumers are interested in clothing that not only looks good but also feels great. The warp yarn is traditionally dyed with the blue pigment obtained from indigo dye. Indigo was the most significant natural dye known to mankind until the introduction of synthetic dyes, at the end of the $19^{\text {th }}$ century [1]. Denim is evergreen classic in the fashion cycle. It has been proved by many fashion designers and the following statements support the same. Denim has now clearly established itself as the definitive "street wear" fabric and has wide age and socioeconomic appeal. Denim mills are now, more than at any time previously, spending large amounts of money in developing new concepts in denim, which in turn means that all jeans manufacturers will experiment with and achieve new levels of finishing [2]. Biopolishing of cotton fabrics with cellulase enzyme results in both beneficial and adverse effects. By suitably optimizing the process conditions, the strength loss during the process can be aimed to a required level, without compromising other handle properties [3]. In the wet processing of denim different mechanical and chemical operations of finishing can be replaced by enzyme treatments, as enzymes are eco-friendly, non toxic, and fully biodegradable compounds. Enzyme technology besides other advantages, also enables process integration [4-7]. The main advantages of enzymes used in denim finishing are efficiency, accelerated reactions, being operational under mild conditions, acting on a specific substrate exclusively, easiness of control, biodegradability, and a wide range of industrial applications. Optimal temperature range for most enzymes is $30-70{ }^{\circ} \mathrm{C}$ under neutral conditions [8-12]. Stretch fabrics are increasingly being used across the whole gamut of clothing applications, such as fashion, sportswear, medical and functional garments [1]. Consumers require that the clothing should satisfy their needs 
in terms of aesthetic appearance, fit and comfort during usage while the clothing manufacturer requires that the fabric is easy to tailor and that the finished garment has a good appearance [13]. The major focus areas of innovation and development are comfort, performance and environment friendliness of different processes. Comfort and fit are very important aspects of denim garments. So, a lot of research has being done to make stretch denims. Recent development of silk denims which are soft, light and comfortable in all seasons, have added a new dimension to the denim and fashion world.

\section{Influence of nano finishes on functional properties}

Denim's popularity to casual dress has also been appreciated in the workplace. Denim is both fashion and performance driven [14]. Therefore, an attempt has been taken to impart some functional effect in denim material using synthesized titanium dioxide nano particles. Nanotechnology is concerned with materials whose structure exhibit significantly novel and improved physical, chemical, and biological properties, phenomena and functionality due to their nano scaled size [15]. The impact of nanotechnology in the textile finishing area has brought up innovative finishes as well as new application technique. The finishes obtained using nanotechnology are claimed to be more durable than conventional ones. These advanced finishes setup an unprecedented level of textile performances of stain-resistant, hydrophilic, antistatic and wrinkle resistant and shrink proof abilities [16]. Nano-size particles have larger surface area and hence higher efficiency than larger size particles $[17,18]$. Nano-size particles are transparent; hence it does not blur colour and brightness of the textile substrate. Some of the textile products based on nanotechnology have just begun to hit the market and it is only a matter of time before one can see a large scale application of nanotechnology not only in textiles, but in applications affecting our day today life.

Growing awareness of health and hygiene has increased the demand for bioactive textiles [19]. With the advent of nano science and technology, a new area has developed in the realm of textile finishing [20]. The UV blocking property of a fabric is enhanced when a dye, pigment, delustrant or UV absorber finish is present in the fabric that absorbs UV radiation and blocks its transmission through the fabric to the skin [21]. The conventional methods used to impart different properties to fabrics often do not lead to permanent effects and it will lose their functions subsequently after laundering or wearing. Nanotechnology can provide high durability for fabrics, because nanoparticles have a large surface area-to-volume ratio and high surface energy, thus presenting better affinity for fabrics and leading to an increase in durability of the function [22]. In addition, a coating of nanoparticles on fabrics will not affect the breathability or hand feel of the fabric [23]. The field of nano finishing in textile technology is very promising due to various end uses like protective textiles for soldiers, medical textiles and smart textiles. With the advancements in synthesis and characterization of various types of nano materials, standardization of application protocol is a must to impart functional finishing to textile materials [24]. In this work an attempt has made to convert the $\mathrm{TiO}_{2}$ particle in to nano $\mathrm{TiO}_{2}$. The synthesized nano $\mathrm{TiO}_{2}$ were applied on the denim fabric and thereby to produce multi-functional effects. The treated material has been studied for their UV protection ability, antimicrobial ability and stain repellent properties and few essential physical properties, to find the effect of treatment on the fabric.

Reversible reaction in semi batch-batch mixed technique has been used for the synthesis of Titanium dioxide nano-particles. The nano particles have been observed to be almost spherical and with a quite narrow size range [25]. SEM technique has been used to study the nano-particles were. Three methods have been used to treat the denim fabric with the synthesised nano particles of titanium dioxide. The methods include direct exhaustion of the $\mathrm{TiO}_{2}$ Nano particles, micro encapsulation of $\mathrm{TiO}_{2}$ nano particles and nano encapsulation of $\mathrm{TiO}_{2}$ nano particles. The multi functional properties such as anti bacterial, UV protection and stain repellency have been used to test the efficiency of $\mathrm{TiO}_{2}$. From the research work, it is evident that there was significant increase in stain release property of the nano $\mathrm{TiO}_{2}$ treated fabrics and it also gives protection to the body against solar radiation and microbes. The result reveals that the multifunctional effect can be imparted to the $100 \%$ cotton denim fabric treated with nano $\mathrm{TiO}_{2}$ without affecting their basic textile characteristic. Various effects such as fading, vintage, streaks, and so on are imparted by washing with enzymes and different chemicals. The investigation provides great potential and show a new path to the denim industry for adding value to the denim products.

\section{Denim fabric from regenerated cellulose}

Investigations have revealed the importance of clothing comfort in deciding customer satisfaction. Today a garment is not merely dictated by its style and durability but also by its clothing comfort. Clothing that is in direct contact with the human body interacts continuously and dynamically with the skin during use. Such interaction between clothing and the human body stimulates mechanical, visual, and thermal sensations, which eventually lead to perception of either comfort or discomfort. Slater has defined clothing comfort as a pleasant state of physiological, psychological, and physical harmony between the human being and the environment [26]. Clothing comfort includes three main considerations: psychological, sensorial, and thermo physiological comfort. It is known that fiber type, yarn properties, fabric structure, finishing treatments, and clothing conditions are the main factors affecting thermo physiological comfort. Sensations that arise from the thermal and moisture transport properties of clothing are important inputs to the perception of state of comfort. An understanding off fabric properties that influence thermal and moisture sensations is essential for engineering fabrics that provide maximum comfort to the wearer. While innovations have been made to offer new 
colors and different look and feel of the denim fabric, not much work is reported to have been done to add comfort to this all-time favourite apparel. Considering the above mentioned facts, this concept "regenerated cellulose-based denim" aims at providing mankind with denim trousers having great comfort. The focus is on studying the comfort aspects of the denim followed by development of a new comfortable product using different types of regenerated fibers with cotton but maintaining the original rugged and rustic look of denim. There search worken visages not only offering more comfortable denim but also providing an alternative to cotton which is already in short supply due to enormous global demand. Regenerated fibers are produced from natural origin such as wood pulp. Very good tensile strength, bright appearance and soft feel are exhibited by such cellulosic fibers. These are resistant to wear and have smooth handle. Besides imparting comfort in moderate conditions such products can transfer moisture well and enable comfort during wear in hot, moist climatic conditions.

Studies have revealed that cellulosic derivatives like modal, bamboo and Tencel yarns have various properties owing to their production methods and raw material but have no remarkable influence on end product. The percentage of moisture in the fiber is determined by the cellulose content, leading to cooling sensation when in contact with the human body [27]. Reduction in hairiness and fineness of yarn will enhance the clothing comfort by providing more area of contact to the wearer. Fabrics having smooth and soft surface would improve the soothing sensation for clothing in tropical regions. The heat conductivity and contact area of the fabric with body are based on thermo physiological properties. Hence in the case of filament fabrics it exhibits most favourable values. Air permeability is a measure of passage of air through the fabric that implies comfort of the clothing with less cover factor. Objective evaluation has been used to determine comfort behaviour of fabrics using Kawabata evaluation. The properties studied include tensile, bending shear, compression and surface properties. The cumulative results will give primary hand values and total hand values. The primary hand values like koshi, shari, and hari have been found to be highest in the denim fabric having indigo dyed cotton warp and viscose filament weft. Gradually decreasing primary hand values have been found in denim fabrics of the following types

a. Indigo dyed cotton warp and viscose weft

b. Indigo dyed cotton warp and bamboo weft

c. Indigo dyed cotton warp and tencel weft

d. Indigo dyed cotton warp and modal weft

e. Indigo dyed cotton warp and grey cotton weft

Fukrami shows fullness, bulkiness of fabrics which is highest with fabrics of the following types

a. Indigo dyed cotton warp and viscose weft

b. Indigo dyed cotton warp and
Hence the following fabrics showed the largest value and contributing towards the comfort ability in summer suiting.

a. Indigo dyed cotton warp and viscose filament weft

b. Indigo dyed cotton warp and tencel weft

\section{Chemical processing of fashion denims}

In a green supply chain the manufactures can encourage the suppliers to adopt green practices and management systems so as to respond to the conscious consumers out there in the market [26]. The leading textile chemical manufacturing industries have been working towards product stewardship in supplying of chemicals that meet the criteria of eco-labels, (Bluesign, Green label, Oeko-Tex, etc) prohibited substances list and are compliant to REACH legislation [28].

Combination of several processes drastically reduces the chemical consumption as well as the water consumption, and finally achieving the required result.

a. Tests have shown that, when we combine Stone wash in addition to the Bleach wash, consumption of water drastically reduces 30 litres per KG of denim Garments.

b. If we combine Biopolishing with the stone washing, we shall achieve the desired effect with saving of at least 30-50L of water per KG of denim garments.

c. With the help of new silicone softeners with remarkable stability which offers several ways to combine treatment baths and thus saving lots of water, energy and chemicals; i.e. saves up to 50 litres of water for every pair of Jeans; Reduce utility costs and Energy Usage; Assists in marketing of Sustainable Denim Garments.

In order to produce more eco-friendly textiles/apparels there is a need for joint effort from retailers and producers. There is a to develop production processes utilizing lower quantities of water, lower chemicals, hazardous chemicals or lower releases of GHG, etc. which is equally important as the measures adopted by retailers, producers and subsequently for consumers to choose such textiles/apparel products [29]. But consumer behaviour in how they care for and dispose of clothing and other textile products is of equal importance, viz. choice of suitable washing temperatures, taking the right steps to significantly extend the lifetimes and encouraging recycling of garments once they have reached the end of their life. In order to enhance the product demand such crucial problems are the areas where retailer's brands can have a high degree of influence on the consumers.

\section{Special finishes on denim}

Application of enzymes in finishing of denim fabrics offer a number of benefits such as efficiency, accelerated reactions, being operational under mild conditions, acting on a particular substrate exclusively, better control, biodegradability, and covering a broad spectrum of industrial uses. In the case of most enzymes, under neutral conditions the optimal temperature lies 
between $30-70{ }^{\circ} \mathrm{C}[30-33]$. It is necessary to avoid back staining during enzymatic treatment as there is possibility of redeposition of the indigo dye that is removed, on the white weft yarn of the denim fabric [34]. The most conventional and primary technique of enzyme application in textile finishing relates to processing with $\alpha$-amylases [35]. In the case of denims and other fabrics produced from cotton and its blends, the warp threads are coated with starch/size, which plays the role of a lubricant and protects the yarn during weaving. The size material has to be stripped off the fabric after weaving [36]. The enzymes used for desizing of cotton are mainly of bacterial origin such as Bacillus subtilis. The starch is hydrolysed by amylases without adverse effects on cotton fabrics $[37,38]$. Based on the type of sugar produced like $\alpha / \beta$-amylases the starch enzymes have been classified [39]. A very thin layer is formed on the surface of denim fabric by leather and wax finish which changes the surface features of the treated fabrics. The strato and the spider finishes are the processes of exhaustion, while the soft resin finish is performed by spraying. The peach skin effect is imparted on denim fabric by leather finish which is a simple and fast surface treatment for producing particular effects. It can be applied partially or completely on the denim fabric surface. Denim treated by wax finish imparts a smooth, greasy and oily feel. The application of special binders and chemicals provides elastic and soft, silicone-like film onto the treated areas. Special resin finishes have been used to impart permanent 3D creases, resistant to wearing and washing. Spraying technique is used for application of resin directly on to denim. Creases can be formed using binder clips or aluminium pipes before or after spraying the resin. Loss of strength of the treated denim is the major setback with spray resin finish. Owing to the interaction with design and its discoloration ability, special finish labelled as strato is an actual and trendy one. Basically, various types of creases are formed with clips or other trimmings (textile tagging gun). Such parts of denim which are not accessible for chemicals (inner parts of the material) are not bleached, and hence the treated areas resemble floating clouds. Crackle effects can be produced by sporadic breaks on the denim pre treated with a special stiffening agent.

Application of special finishes on denim leads to attractive and respectable patterns as important design elements. Considerable differences have been observed between special treatments as revealed by results of spectral values [40]. Strato, leather and wax finishes can produce special effects that are acceptable based on technological indicators. Resin and the spider finish affect fabric weight and reduce its strength and usability in garments. Hence, such effects can only be applied as effective parts or segments of a garment.

\section{Studies on stretch denim fabrics}

The capability of a fabric to recover from induced wrinkles or to retain a smooth surface appearance after wear and repeated laundering is considered to be one of the factors that influences clothing $[41,42]$. During garment wear the fabrics are expected to stretch as per body movements and after stretching be able to retain the original shape without getting deformed. Hence, the extension and recovery properties after repeated stretch are considered crucial for the performance and appearance of garments [43]. The stretch and high elastic recovery fabrics have been introduced in the market so as to avoid deformation and decrease bagging and dimensional changes [42,44]. Elastane fibres are characterized by superior stretch and excellent elastic recovery properties. Elastane fibres are mostly used in conjunction with other fibres to achieve controlled stretch and recovery properties and to protect the elastane from mechanical damage $[45,46]$. In comparison with $100 \%$ cotton fabrics, elastane blended fabrics exhibit greater extension, immediate recovery, and resiliency [47].

The extension or stretch applied to woven fabrics during manufacturing, finishing, garment construction, and wear is generally within the low stress region. The KES-F system is a device capable of measuring the low stress tensile, shear, bending and compression deformations of fabrics [48]. With the information provided by this system it is possible to specify fabric handle repeated performance requirements and transactions based on fabric mechanical properties [49].

The clothing engineers have tried to apply the mechanical parameters to tailoring process control and have also attempted to connect these parameters with suit appearance [11]. It was reported that the ideal fabric satisfies the three conditions, namely, good hand, good appearance of suit and mechanical comfort for wear. The mechanical comfort is expressed by a range of fabric mechanical parameters such as tensile properties.

Investigations on the stretch denim fabrics have shown that in order to improve tensile recovery properties, it is necessary to have higher polyester and lower cotton content, lower linear density, and density of weft yarns but higher density of warp yarns. The structure of the fabric needs to have less tightness so as to achieve higher tensile resilience, degree of elasticity and also lower residual strain. Tightness of fabrics can be studied using density multiplied by linear density, because there exists strong linear relationship between cover factor and density. In the study of recovery, residual strain alone cannot be used since the crucial aspect is percentage of return after stretching to the whole investigation [48]. Hence it is necessary to calculate the degree of elasticity. Degree of elasticity is related to tensile resilience. In other words tensile resilience is related to degree of elasticity. By setting specific modulus of elasticity at the yield point strain and using initial region of tensile curve the tensile resilience can be studied. The tensile strain at yield point varies inversely as the specific modulus of elasticity. This relation could be described by a power function for all tested stretch denim fabrics. When the tensile strain at yield is higher, the degree of elasticity is also higher, if elastane is not used, but it is lower if elastane is used. When elastane is used the degree of elasticity increases with increase in the specific modulus of elasticity, and is lower when elastane is not used. Hence, higher specific 
modulus of elasticity with elastane ensures better tensile elastic recovery.

\section{Improvement in pre and post processes of denim}

The increase in demand of denim fabrics has prompted great challenge on the part of denim product manufactures to innovate and develop products to suit requirements of different consumers. The major focus areas of innovation and development are comfort, performance and environment friendliness of different processes [49]. Comfort and fit are very important aspects of denim garments. So, a lot of research has being done to make stretch denims. Elastane fibers are incorporated into the fabric. Lycra and Spandex are used in weft yarn. Ring and openend core spun yarns are also used in denim to provide stretch property. Elastic ply yarns produced on TFO are also used to make stretch denim fabrics. Apart from the multi-component, Bi component synthetic filament yarns are also used to provide stretch.

To improve performance, synthetic fibers blended with natural fibers are used. One of such blends is blend of Nylon 6.6 and cotton. This fabric shows the traditional look and feel but performance is better than the 100 per cent cotton denim in terms of better abrasion resistance. So, the durability of the fabric is more than the $100 \%$ cotton denim [50,51]. Other synthetic fibers such as polyester and polypropylene fibers are also used. For making softer denim fabrics especially for women wear, blend of Cupro, Modal, Promodal, Tancel, and Rayon are being used. Bamboo fibers, hemp fibers and their blends are being used to make denim fabrics.

To impart fancy effect, different kinds of fancy yarns are being used. The examples of such yarn are slub yarn and multicount yarn [52]. The slub can vary in terms of thickness, length and twist. Such yarns can be manufactured at ring spinning and OE spinning machines by attaching special attachment. One of such attachments is Amsler control. Such fabrics give very unique effect after washing treatment.

Two methods of warping are practiced. These are ball warping and direct warping. Dyeing of warp yarns is done either by rope dyeing method or Slaser dyeing method. Rope dyeing is considered better in many aspects such as higher production, long runs, better dry and wet fastness and lot-to-lot shade consistency. Indigo dyes are generally used to dye warp yarns. In some cases sulphur black and blue dye can also be applied before indigo dyeing to achieve darker shades. Sometimes, sulphur dyes are also applied after the yarn is indigo dyed.

A lot of research is taking place to develop dyeing process which produces low impact on environment. Clariant has developed a range of low sulphide dyestuff and process to obtain various indigo shades at low dyeing cycle to reduce the consumption of water. Dyester has patented Indigo Vat $40 \%$ solution. It offers various shades of blue and claims $60-70 \%$ reduction in consumption of Sodium hydrosulphite.
Denim fabrics are mostly woven on high speed air-jet looms. Various loom manufacturers are offering a number of modifications to weave fault free high quality fabric. The modifications are done in the frame structure of loom to minimize vibrations, pre-winder, auxiliary nozzles, stretch nozzles, relay nozzles and weft brake system. Traditionally denim is $3 / 1$ right hand twill fabric [53]. Nowadays $2 / 1$ twill, broken twill, zig-zag twill, reverse twill, Herringbone twill weaves are used in denim fabrics.

Desizing of fabrics is done after weaving. This process can be done by acid desizing method and oxidative desizing method. But these processes are associated with a number of disadvantages. To overcome this, enzymatic desizing is preferred. Alphaamylase is used as desizing agent. Enzymatic process are more eco-friendly than chemical methods.

Washing of denim garments is one of the most important processes. This process adds a lot of value to the final garment. In the washing process, fading effect is imparted to the denim products. There are many methods to impart faded effects [54]. The traditionally washing is done using any of the methods or combinations such as stone washing, washing with strong bleaching agents such as sodium hypochlorite, potassium per magnet. These processes are not environment friendly. Alternative methods have been developed. Cellulases enzymes are used in place of pumice stone to impart abraded effect.

Laccase based bleaching technique is developed. This enzyme only attacks indigo dyed yarn bit does affect nature of white weft yarn $[55,56]$. It can also be used to bleach fabrics containing elastane filaments without losing stretch property. Laser based techniques are used to give faded effect. Further this technique can also be used to create motifs on the denim fabrics. Ozone base denim washing treatments have been developed. In this process, ozone gas is used as bleaching agent, which attacks indigo dyes and destroy to create faded look.

Functional finishes such as antibacterial finishes, UVprotection finishes are applied on denim fabrics to improve functional performances of denim fabrics [57]. To enhance the durability of the finished fabric, nano encapsulation of the herbal extracts were performed and the results showed good resistance for microbes even after 30 industrial washes. The use of nanoclay is also reported to impart old look, soft handle, flame retardant and antibacterial properties to denim fabrics.

\section{Silk denims}

In the present global economy, the future of silk will increasingly depend on the industry's ability to relentlessly innovate new range of products. Product development has been a pressing need of the Indian silk industry and diversification into casual wear to address the changing market needs is critically important. The silk denim fabrics were converted into mens' shirts, trousers, jackets, kids wear, ladies skirts and tops. The garments were finished with enzyme treatment, acid wash, 
softening treatment with silicon softener. The silk denim fabrics in the weight range of $100-120 \mathrm{gsm}$ are suitable for mens' shirts, ladies tops and children's garments while the heavier varieties (above 120gsm) are more suitable for trousers, skirts, jackets etc.

The denim is a coarse twill weave cotton fabric, also commonly known as blue jeans/jeans. Taking clue from the history that denims/jeans were originally made of silk, wool, cotton and linen, an attempt has been made to develop different combinations of silk denim fabrics [58]. The mulberry silk of $20 / 22$ denier in 6 and 12 ply organzine twisted and eri silk of $2 / 60$ s, 2/80s and 2/ 120s were used in warp. The warp yarn was dyed to indigo blue shade with acid dyes. The mulberry silk in 6 and 12 ply tram twisted and eri silk of $2 / 60$ s, 2/80s and $2 / 120$ s grey yarns were used in weft for development of $100 \%$ silk denim fabric. The cotton yarn of 2/60s, 2/ $100 \mathrm{Ne}$ and linen yarns of $40 \mathrm{~s}, 50 \mathrm{~s}$ Le were also used in weft on the silk warp. Further, mulberry raw silk of 20/22 denier that can be doubled and twisted in the required plies and eri mill spun silk yarn available in the counts of $2 / 40 \mathrm{~s}, 2 / 60 \mathrm{~s}, 2 / 80 \mathrm{~s}, 2 / 100 \mathrm{~s}$ and $2 / 120 \mathrm{~s}$ $\mathrm{Nm}$ and 20s Ne noil yarn can also be used for development of different varieties of silk denim fabrics. Silk denim fabrics in 14 combinations in the weight range of 100 to $300 \mathrm{gsm}$ were developed with $100 \%$ mulberry silk, $100 \%$ eri silk and their combination with cotton and linen as union fabrics. These denim fabrics were woven on rapier loom having width of 44 inches and 3/1 twill weave. The 20s $\mathrm{Nm}$ erinoil yarn was also used in the weft which gave the slub and fancy effect to the denim fabric. Thus, denims originally considered as rough and tough, and more suiting to work and casual wears are gradually finding their way into fashion wear. The silk denim garments are soft to touch, light in weight, comfortable to wear in all the seasons, blended with the luxury and smooth feel. The eri silk has thermal properties nearly equivalent to wool which makes $100 \%$ eri silk denim garments apt for winter. The silk x cotton and silk x linen union denim fabrics are more cost-effective without losing their comfort and silky appearance. These new products will add a new dimension to the denim and fashion world in general and silk and silk blended products, in particular, and open up a whole new range of fabric to the younger generation.

\section{Conclusion}

The popularity of denim fabric from casual wear to work place has been well known. It is both fashion and performance driven. Effort has been taken to impart multi functional finish on denim fabric for value addition using titanium dioxide. The nano titanium dioxide treated fabrics exhibit good stain release property and also provides protection to the human body against UV radiation and microbial protection as well. Hence the single entity serves as a multi functional property to the denim world. Garments with multiple permutations and combinations of denim fabric variables like fibers, yarns, and Lycra \% and weaving techniques are available with differing garment design statements, but the comfort aspect is slightly ignored. To cater to the masses living in hot and humid areas, a denim fabric is being projected with varying garment constructional parameters. Regenerated cellulose-based fibres/yarns are considered as eco-friendly, cool, soft, fairly strong, and durable among other manmade and natural fibre based yarns. Effort has been taken to develop comfortable denim clothing using regenerated cellulose fibre derivatives, maintaining its traditional rustic look for tropical regions. Fabric performance evaluation methods have been used to ascertain the performance of the newly developed clothing. It has become necessary to study of various techniques through which apparel industries are developing textiles with smart functioning, using new sustainable products to provide extra comfort and increased performance in an eco-friendly manner. Sustainability will be new key word or essential for all the denim/jeans brands/Denim manufacturers to withstand in the global environment. Novel finishes have been applied on denim fabrics. The impacts of the finishes are related to breaking force, spectral characteristics, and surface appearance. Significant differences have been noticed in comparison with modern finishing treatments and indicate in an effective segment of the garment sector only. The resilience properties of stretch denim fabrics have been studied on the basis of tensile properties and structural parameters. Recent development of silk denims which are soft, light and comfortable in all seasons, have added a new dimension to the denim and fashion world.

\section{References}

1. http://www.denverfabrics.com/content/denim/denim.aspx.

2. Roshan P, Sandeep NR, Jegadeesh T (1996) Denim: The evergreen farourite, Textile Dyer \& Printer.

3. Chinta SK, Landage SM, KetanVerma (2012) Article published in the Textile review magazine.

4. Mazumder S (2010) Daffodil international University of Science and Technology 5: 6 .

5. Losonczi A, Csiszar E, Szackacs G, Kaarela O (2004) Textile Research Journal 74: 501.

6. Ismail OE, Ozguney AT, Arabaci A (2007) AATCC Review 7: 39.

7. Dekanic T, Soljacic I, Pusic T (2007) Tekstil 57: 226.

8. Ayaz sheikh M (2010) Pakistan textile journal 59: 48.

9. Schemidt M (1995) Melliand international 1: 116.

10. Sariisik M (2004) AATCC Review 4: 24.

11. Erkan G, Saarisik M (2004) AATCC Review 4: 17.

12. Gusakov A, Sinitsyn A, Grishutin S, Tikhomorov D, Shook D, et al. (2000) Textile chemists colorists American dyestuff reporter 32: 42.

13. Watkins $P$ (2011) Indian journal of fibres and textile research 36: 366.

14. Virginia SB (2002) It 39s in the Jeans. Textile world.

15. Wang ZL (2001) Characterization of Nano Phase Material Wiley-VCH Verlag GmbH, Germany.

16. Wong YWH, Yuen CWM, Leung MYS, Ku MYS, Lam HLI (2006) Selected applications of nanotechnology in textiles. Autex research Journal 6(1): 1-8. 
17. Purwar R, Joshi M (2004) Recent developments in anti-microbial finishing of textiles - A Review. AATCC Review 4: 22-26.

18. Vigneshwaran N, Sampathkumar, Kathe AA, Varadarajan PV, Virendra P (2006) Functional finishing of cotton fabric using zinc oxide - soluble starch nano composites. Nanotechnology 17: 5087-5095.

19. Hustvedt C, Crews PC (2005) Ultra-violet protection factor of naturally pigmented cotton. Journal of cotton science 9(1): 47-55.

20. Jeevani T (2011) Nanotechnology in Agriculture. Journal of Nano medicine and Nanotechnology 2: 124.

21. Amy Frederick (2011) Smart Nanotextiles: Inherently Conducting Polymers in Healthcare. Da Vinci's Notebook 3: 1-2

22. Kathirvelu S, D’Souza L, Dhurai B (2008) Nanotechnology applications in textiles. Indian Journal of Science and Technology 1(5).

23. Ki Do kim, Jae-Bok Lee, Hee Taik Kim (2001) Synthesis of Titanium Dioxide Nanoparticles by reversible reaction in semibatch-batch mixed method. J Ind Eng Chem 7(3): 153-159.

24. Vijayalakshmi D, Rathinamoorthy R, Ramachandran $T$ (2012) An Experimental Study on the Multi-functional Efficacy of Nano TiO2 Treated Denim Fabrics. Journal of Textile and apparel, technology and management 7(4): 1-12.

25. Vivekanadana MV, Raj S, Suffixeenivasan S, Nachane RP (2011) Parameters affecting warm-cool feeling in cotton denim fabrics. Indian Journal of Fibre \& Textile Research 36(2): 117-121.

26. Annu K, Karan K (2016) Regenerated Cellulose-Based Denim Fabric for Tropical Regions: An Analytical Study on Making Denim Comfortable. Journal of Textiles p. 10.

27. Sustainable fashion meets eco-friendly energy (2009).

28. Levi’s (2013) Sustainability | Levi Strauss \& Co.

29. Shekar KE (2014) Study on sustainability of processing eternal fashion jeans. International journal of management and Social Science Research Review 1(4): 229

30. Cavaco Paulo A, Morgado J, Almeida L, Kilburn D (1998) Textile Research Journal 68: 398

31. Wang N, Xu Y, Lu DN, Xu JH (2004) AATCC Review 4: 28.

32. Ayaz Sheikh M (2010) Pakistan Textile Journal 59: 48.

33. Erkan G, Saarisik M (2004) AATCC Review 4: 17.

34. Gusakov A, Sinitsyn A, Grishutin S, Tikhomirov D, Shook D, et al. (2000) Textile chemists and colorists American dyestuff reporter 32: 42.

35. Schmidt M (1995) Melliand International 1: 116.
36. Araujo R, Casal M, Cavaco Paulo A (2008) Biocatalyst Biotransfor 26: 332.

37. Maryan AS, Montazer MA (2013) Cleaner production 57: 320.

38. Mahato D, Colourage (2005) 52: 79

39. Cavaco Paulo A, Gubitz GM (2003) Textile processing with enzymes (Wood head publishing ltd., Cambridge).

40. Dekanic T, Pusic T, Soljacic I (2015) Influence of special finishes on denim properties. Indian journal of fibre and textile research 40: 170 .

41. Fan J, Yu W, Hunter L (2004) Clothing appearance and fit: Science and Technology (Wood head publishing, Cambridge).

42. Ozdil N (2008) Fibres Textile Eastern Europe 16(1): 63.

43. Tsai I, Chun D, Cassidy C, Cassidy T, Shen J (2002) Transaction instrument measurement and control 24(1): 3.

44. El-Ghezal S, Babay A, Dhouib S, Cheikrouhou M (2009) Journal of textile institute $100(3): 245$.

45. Bilal Q, Tanveer H, Mumtaz M (2014) Journal of engineered fibres and fabrics 9(1): 23

46. Abdessalam SB, Abdelkader YB, Mokhtar S, Elmarzougui (2009) Journal of engineered fibres and fabrics 4(4): 30.

47. Mukhopadhyay A, Sharma IC, Mohanty A (2003) Indian journal of fibres and textile research 28(4): 423.

48. Kristina A, Marie K, Antonin H (2017) Indian journal of fibres and textile research 42:175.

49. Tarafder, Nemailal (2008) Man-Made Textiles in India 51(11): 387

50. Textile Magazine (2013) 54(5): 48.

51. Apparel (2014) 55(12): 32.

52. (2014) Indian Textile Journal.

53. Darji, Alkesh (2014) Melliand International 20(1): 44.

54. Sumithra M, Raaja NV (2012) Man-Made Textiles in India. 40(4): 131.

55. www.fiber2fashion.com

56. Maryan, Ali Sadeghian, Montazer Majid, Rashidi Abousaid (2013) Journal of Engineered Fabrics \& Fibers (JEFF) 8(4): 68-77.

57. Sariisik, Merih (2004) AATCC Review 4(1): 24-29.

58. http://www.fibre2fashion.com/services/article-writing-service/ content-promotion-services.asp.
This work is licensed under Creative

Commons Attribution 4.0 Licens

DOI: 10.19080/CTFTTE.2018.02.555592
Your next submission with Juniper Publishers will reach you the below assets

- Quality Editorial service

- Swift Peer Review

- Reprints availability

- E-prints Service

- Manuscript Podcast for convenient understanding

- Global attainment for your research

- Manuscript accessibility in different formats ( Pdf, E-pub, Full Text, Audio)

- Unceasing customer service

Track the below URL for one-step submission https://juniperpublishers.com/online-submission.php 